\title{
Anti-reflux Surgery Versus Proton Pump Inhibitors for Severe Gastroesophageal Reflux Disease: A Cost-Effectiveness Study in Korea
}

\author{
Susan Park, ${ }^{1}$ Sungsoo Park, ${ }^{2}$ Joong-Min Park, ${ }^{3}$ Soorack Ryu, ${ }^{4}$ Jinseub Hwang, ${ }^{4}$ Jin-Won Kwon, ${ }^{1 *}$ and Kyung Won Seo ${ }^{5 *}$ \\ ${ }^{1}$ College of Pharmacy and Research Institute of Pharmaceutical Sciences, Kyungpook National University, Daegu, Korea; ${ }^{2}$ Department of \\ Surgery, Korea University College of Medicine, Seoul, Korea; ${ }^{3}$ Department of Surgery, Chung-Ang University College of Medicine, Seoul, Korea; \\ ${ }^{4}$ Division of Mathematics and Big Data Science, Daegu University, Daegu, Korea; and ${ }^{5}$ Department of Surgery, Kosin University College of \\ Medicine, Busan, Korea
}

\section{Background/Aims}

The economic burden for gastroesophageal reflux disease (GERD) has recently increased in Asian countries. This study investigates the cost-effectiveness between anti-reflux surgery and medication, with proton pump inhibitors (PPIs) for GERD in Korea.

\section{Methods}

We used a decision tree and Markov model to obtain the costs and quality-adjusted life years (QALYs) of the surgical and medical strategies. Our target cohort was the severe GERD patients aged 50 years old who required a continuous double dose of PPIs. The time horizon was 10 years and all estimates were discounted at $5 \%$ per year. The incremental cost-effectiveness ratio of the anti-reflux surgery compared with medication with PPIs was calculated. Sensitivity analyses were performed on all relevant variables.

\section{Results}

The cost-utility analysis indicated anti-reflux surgery was more cost-effective than medication among severe GERD patients over a 10year period. The model predicted that the surgical strategy had a cost savings of \$551 and the QALYs had a gain of 1.18 as compared with the medical strategy. The break-even point in costs of the anti-reflux surgery over the medication was estimated to be 9 years. Sensitivity analyses using the varying parameter assumptions demonstrated the robustness of the study results.

\section{Conclusions}

This study showed anti-reflux surgery was less expensive and more effective therapy over the PPI medication after 9 years of follow-up. This suggests the surgical strategy is a cost-effective alternative to PPI medication among patients who need long-term management for GERD in Korea.

(J Neurogastroenterol Motil 2020;26:215-223)

\section{Key Words}

Quality-adjusted life years; Cost of illness; Gastroesophageal reflux disease; Proton pump inhibitors

Received: September 26, 2019 Revised: December 30, 2019 Accepted: January 5, 2020

(.) This is an Open Access article distributed under the terms of the Creative Commons Attribution Non-Commercial License (http:// creativecommons. org/licenses/by-nc/4.0) which permits unrestricted non-commercial use, distribution, and reproduction in any medium, provided the original work is properly cited.

${ }^{*}$ Correspondence: Jin-Won Kwon and Kyung Won Seo are equally responsible for this study. Jin-Won Kwon, PhD

College of Pharmacy and Research Institute of Pharmaceutical Sciences, Kyungpook National University, 80 Daehak-ro, Daegu 41566, Korea

Tel: +82-53-950-8580, Fax: +82-53-950-8557, E-mail: jwkwon@knu.ac.kr

Kyung Won Seo, MD, PhD

Department of Surgery, Kosin University College of Medicine, 262, Gamcheon-ro, Seo-gu 49267, Busan, Korea

Tel: +82-51-990-6782, Fax: +82-51-246-6093, E-mail: kwseo@kosin.ac.kr 


\section{Introduction}

Gastroesophageal reflux disease (GERD) is a common and chronic problem of the upper gastrointestinal tract worldwide. ${ }^{1} \mathrm{~A}$ recent review on the global epidemiology of GERD reported that the pooled prevalence of the disease was $17.1 \%, 15.4 \%$, and $10.0 \%$ in Europe, North America, and Asia, respectively. Although its prevalence has been relatively low in Asia, the increasing trend has been remarkable recently. ${ }^{3}$ In Korea, the prevalence of physician-diagnosed GERD has increased from $4.6 \%$ to $7.3 \%$ between 2005 and 2008 .,

GERD patients use as-needed or scheduled medication, particularly proton pump inhibitors (PPIs), to control symptoms through reducing acid production in the stomach, which results in increased medical expenditures. ${ }^{6}$ In the United States alone, total medical expenditures of GERD accounted for approximately \$15-20 billion and the drug costs for PPIs exceeded $\$ 10$ billion per year. With an increasing prevalence in Korea, annual expenditures for PPIs dramatically increased from $\$ 25000$ to $\$ 4450000$ between 2002 to $2013{ }^{8}$. However, up to $40 \%$ of patients report persistent symptoms despite PPI therapy. ${ }^{9}$ Furthermore, numerous studies have been published warning of adverse effects caused by the continued use of PPIs. ${ }^{10}$ Anti-reflux surgery has been considered for GERD treatment and many studies have revealed its long-term effectiveness and safety. ${ }^{11,12}$

In light of the increasing prevalence and economic burden, it is crucial to evaluate the cost-effectiveness of treatment strategies for GERD. Numerous studies compared the costs and effectiveness between the surgical and medical therapies for GERD in Western countries. ${ }^{13}$ They showed that costs and health outcomes vary across populations and health care environments, but similar studies conducted in Asia are scarce. Thus, this study aims to evaluate the costeffectiveness of anti-reflux surgery and PPIs medication for severe GERD patients in Korea.

\section{Materials and Methods}

\section{Model Design}

We compared 2 alternative strategies for GERD treatment: (1) medical treatment which uses PPIs, including lansoprazole, dexlansoprazole, omeprazole, pantoprazole, s-pantoprazole, rabeprazole, ilaprazole, or esomeprazole, and (2) surgical treatment which uses anti-reflux surgery. Their time horizon was 10 years with a cycle length of 1 year. The starting age of the cohort was 50 years, based on the mean age of all patients under consideration for receiving anti-reflux surgery due to severe GERD in Korea. Health benefits were quantified in terms of quality-adjusted life years (QALYs), and costs were assessed from the perspective of the healthcare system.

Figure 1 shows the model structure comprised of a decision

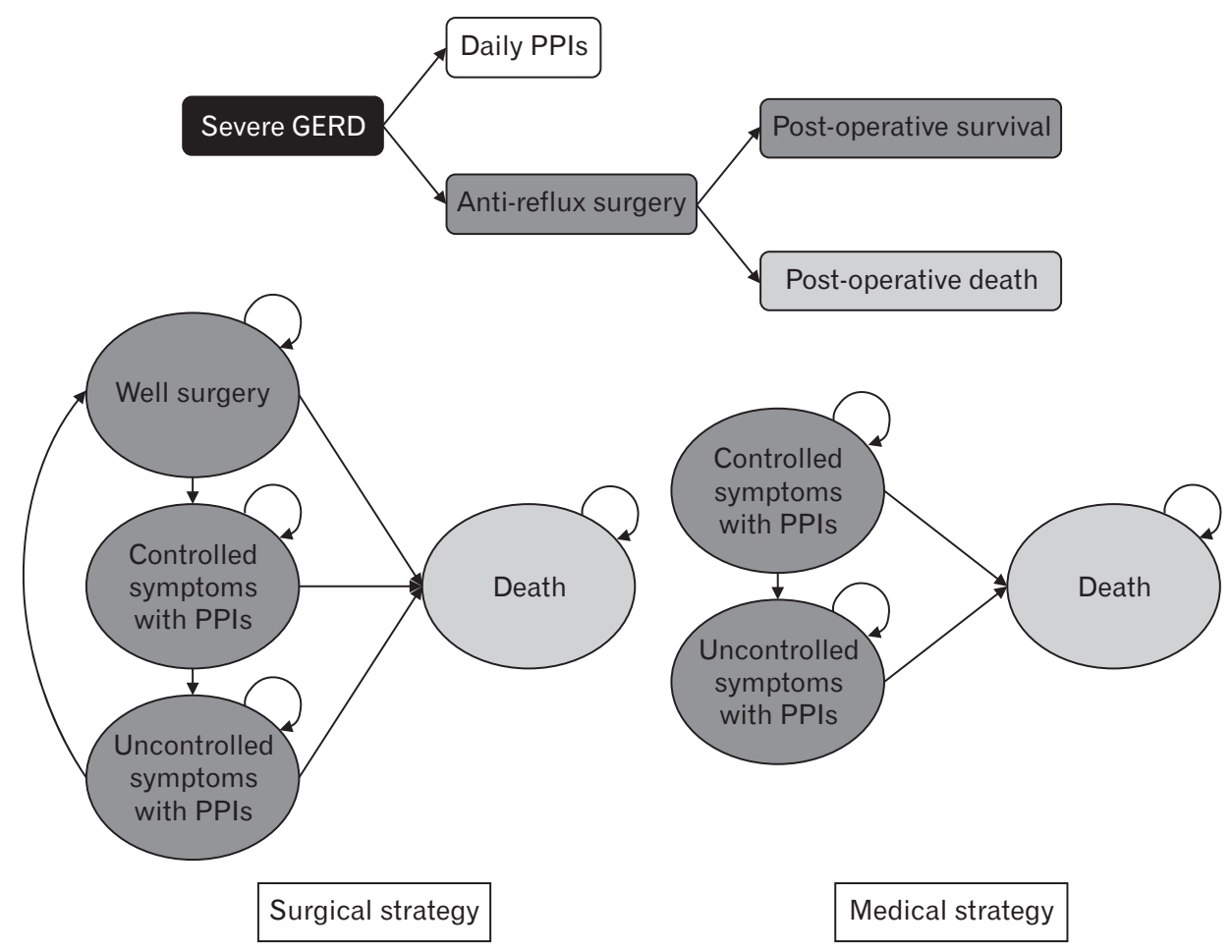

Figure 1. Model structure. GERD, gastroesophageal reflux disease; PPIs, proton pump inhibitors. 
tree for 1 year and Markov cycles for 9 years. First, the decision tree allocated the severe GERD patients to either of the 2 alternative strategies and each cohort then enters the Markov cycle. Severe GERD was defined as having symptoms, including heartburn and regurgitation that require either a continuous double dose of PPI or surgical treatment. In the Markov model, the surgical strategy had 4 health statuses such as surgery, controlled symptoms with PPIs, uncontrolled symptom with PPIs, and death. Patients who corresponded to uncontrolled symptoms with PPIs received more than a triple dose of PPI or chose the repeat operation. The medical strategy included 3 health statuses, controlled symptoms with PPIs, uncontrolled symptoms with PPIs, and death. The option of surgery after treatment failure was not considered in the medical treatment strategy. In the baseline case model, future costs and health benefits were discounted at $5 \%$ per year, according to Korean guidelines for economic evaluation. The model was developed using Microsoft Excel.

This study is an economic evaluation using secondary data (data that have already been collected and available from our previous researches), ${ }^{14,15}$ therefore, informed consent could not be obtained from each patient. This study was approved by the Institutional Review Board of Kosin University Gospel Hospital (IRB No. KUGH 2018-02-013).

\section{Evidence Used in the Model}

Evidence including transition probabilities, costs, and utilities, was derived from the literature review and data analysis in part of the Korea Health Technology R\&D Project (HC17C0050). In the project, clinical data, including quality of life (QoL), were collected from 54 patients who underwent anti-reflux surgery at 5 medical centers from January to October 2019 in Korea. Costs and health care utilization were analyzed using a customized cohort dataset that was extracted from the 2007-2016 National Health Insurance Database (NHID). The data for our analysis contained all GERD patients who underwent anti-reflux surgery $(\mathrm{n}=342)$ and a $25.0 \%$ random sample of all GERD patients with PPI medication $(\mathrm{n}=$ 775 889) in Korea.

\section{Costs}

The economic evaluation was based on a gross cost method using the average medical expenditures for GERD treatment by the surgical and medical groups. In order to calculate the average medical expenditure, the total sum of inpatient costs, outpatient costs, and PPI costs were divided by the follow-up periods (Supplementary Table 1). In the surgery group, the average medical expenditures were analyzed into 3 parts (operation costs, costs within the first year after surgery, and costs from the second year after surgery) for distinguishing between the costs for the surgery and the follow-up care. Refractory GERD is an important indication for anti-reflux surgery; therefore, the cost assumption for severe GERD with PPI medication was based on the definition of refractory GERD, which requires a double PPI dose for at least 12 weeks. ${ }^{16}$ Average medical expenditures were estimated based on 41 months of mean followup time according to 3 levels of a prescribed daily dose (PDD) of PPIs as follows: (1) less than standard dose, (2) from standard to less than double doses, (3) from double to less than triple doses, and (4) more than triple doses. To calculate the PDD, the sum of the doses of each active ingredient in PPIs were calculated for the 12 consecutive weeks during the prescription period. The standard dose of PPIs was defined based on a clinical guideline for GERD in Korea: omeprazole $20 \mathrm{mg}$, lansoprazole $30 \mathrm{mg}$, pantoprazole 40 $\mathrm{mg}$, rabeprazole $20 \mathrm{mg}$, or esomeprazole $40 \mathrm{mg}$ once a day. ${ }^{17}$

We also analyzed health care utilization including inpatient visits, outpatient visits, and emergency room visits, which were used for estimating the transportation costs (Supplementary Table 2). In the baseline case model, the cost estimations for each health status are summarized in Table 1. The costs of productivity loss were not valued due to their high uncertainty.

Medical costs were presented as United States dollars, which were calculated based on an exchange rate of Korean Republic won $1000=\$ 1$.

\section{Transition Probability}

The probabilities of both operative-death and repeat operations were obtained from the 2007-2016 NHID-customized data containing both the medical and vital records of all Korean patients who underwent the anti-reflux surgery. The operative mortality was defined as any death, regardless of cause, occurring within 30 days after surgery. ${ }^{18}$ In our analysis, death cases were not observed either within 30 days as well as within 90 days after surgery. Thus, we assumed that the operative mortality was zero in the baseline case model. For the sensitivity analysis, the probability of operative death was assumed to be 0.008 , based on a previous study on complications of anti-reflux surgery using an administrative database. ${ }^{19}$ The rate of repeat operation was also analyzed, and we checked 7 cases of repeat operation, with an average follow-up of 2.9 years. Thus, the re-operative probability was estimated at $0.7 \%$ per year according to the standard method of conversion between the rate and probability. $^{20}$ Other transition probabilities, such as symptom relapse after medication or surgical treatment, were derived from the clinical tri- 
Table 1. Baseline Case Estimates for Costs, Transition Probabilities, and Utility Weights Used in Model

\begin{tabular}{|c|c|c|}
\hline Category & Value (range) & Reference \\
\hline \multicolumn{3}{|l|}{ Costs (per year) } \\
\hline \multicolumn{3}{|l|}{ Decision tree arm } \\
\hline \multirow[t]{3}{*}{ Surgery group } & $\$ 5445.6$ & Surgery costs \\
\hline & & Costs within the first year after surgery \\
\hline & & Transportation costs for surgery and health care utilization of surgery group \\
\hline \multirow[t]{2}{*}{ Medical group } & $\$ 1166.2$ & Costs for PPIs users (PDD from double to less than triple doses) \\
\hline & & Transportation costs for health care utilization of medical group \\
\hline \multicolumn{3}{|l|}{ Markov status } \\
\hline \multirow[t]{2}{*}{ Surgery group: well-surgery } & $\$ 472.2$ & Costs over the first year after surgery \\
\hline & & Transportation costs for health care utilization of surgery group \\
\hline \multirow[t]{3}{*}{ Surgery group: re-operation } & $\$ 4973.4$ & Surgery costs \\
\hline & & $\begin{array}{l}\text { Excess costs for the first year after surgery compared with costs for more } \\
\text { than second follow-up year after surgery }\end{array}$ \\
\hline & & Transportation costs for surgery \\
\hline \multirow{2}{*}{$\begin{array}{l}\text { Surgery group: controlled symptoms } \\
\text { with PPIs }\end{array}$} & $\$ 1166.2$ & Costs for PPIs users (PDD from double to less than triple doses) \\
\hline & & Transportation costs for health care utilization in medical group \\
\hline \multirow{2}{*}{$\begin{array}{l}\text { Surgery group: uncontrolled symptoms } \\
\text { with PPIs }\end{array}$} & $\$ 1556.7$ & Costs for PPIs users (PDD more than triple doses) \\
\hline & & Transportation costs for health care utilization in medical group \\
\hline $\begin{array}{l}\text { Medical group: controlled symptoms } \\
\text { with PPIs }\end{array}$ & $\$ 1166.2$ & Same as above (surgery group: symptom recurrence) \\
\hline $\begin{array}{l}\text { Medical group: uncontrolled symptoms } \\
\text { with PPIs }\end{array}$ & $\$ 1556.7$ & Same as above (surgery group: symptom uncontrolled) \\
\hline \multicolumn{3}{|l|}{ Transition probability (per year) } \\
\hline \multicolumn{3}{|l|}{ Decision tree arm } \\
\hline Death due to surgery & $0.000(0.000-0.000)$ & 2007-2016 NHIS-customized data \\
\hline \multicolumn{3}{|l|}{ Markov status } \\
\hline Re-operation rate & $0.007(0.001-0.012)$ & 2007-2016 NHIS-customized data \\
\hline $\begin{array}{l}\text { Symptom relapse rate } \\
\text { after surgery }\end{array}$ & $0.032(0.021-0.041)$ & Galmiche et al, $2011^{21}$ \\
\hline $\begin{array}{l}\text { Symptom uncontrolled rate } \\
\text { with medication }\end{array}$ & $0.017(0.008-0.023)$ & Galmiche et al, $2011^{21}$ \\
\hline Death & Life table & Mortality rate derived from age and sex matched life expectancy \\
\hline \multicolumn{3}{|l|}{ Quality of life (utility weights) } \\
\hline \multicolumn{3}{|l|}{ Decision tree arm } \\
\hline Surgery group & 0.884 & $\begin{array}{l}\text { A survey on EQ-5D-5L for } 51 \text { patients underwent the anti-reflux surgery } \\
\text { (preference score at } 2 \text { weeks after surgery } \times[14 / 365])+(\text { preference score at } 3 \\
\text { months after surgery } \times[351 / 365])\end{array}$ \\
\hline Medical group & 0.725 & Preference score in patients with good PPI effect \\
\hline \multicolumn{3}{|l|}{ Markov status } \\
\hline Well surgery & 0.887 & Preference score at 3 months after surgery \\
\hline Symptom control with double doses & 0.725 & Preference score in patients with good PPI effect \\
\hline Symptom control with triple doses & 0.707 & Preference score in patients with poor PPI effect \\
\hline
\end{tabular}

PPI, proton pump inhibitors; PDD, prescribed daily dose; NHIS, National Health Insurance Service.

Table 2. Results of Cost-Effectiveness Analysis (Time Horizon: 10 Years)

\begin{tabular}{lccccc}
\hline Treatment group & Cost $(\$)$ & Incremental cost & QALY & Incremental QALY & \$/QALY \\
\hline Medication & 10247 & & 5.87 & & \\
Surgery & 9696 & -551 & 7.05 & 1.18 & Surgical-dominated \\
\hline
\end{tabular}

QALY, quality-adjusted life year. 
als conducted by Galmiche et $\mathrm{al}^{21}$ because of the high similarity of the study design to our research. The mortality rates in the model were based on the lifespan table of the Korean population in 2016 provided by the Korean Statistical Office (http://kostat.go.kr).

\section{Utility}

Utility values were estimated based on QoL measured by the generic instrument of EuroQol EQ-5D-5L administered at baseline, 2 weeks and 3 months after surgery (Supplementary Table 3). Each of the possible health statuses of EQ-5D-5L was mapped to a preference based value (zero represents a state of death and one represents perfect health). We used a standard value set of EQ5D-5L for the Korean population to calculate the preference score, according to the recommendation of the EuroQol Group. ${ }^{22}$

\section{Sensitivity Analysis}

One-way sensitivity analyses were performed to assess the impact of varying treatment costs, transition probabilities, utility weights, and time horizons. It targeted the parameter assumptions that varied $\pm 25 \%$ from both the surgical and medical strategies in the baseline case model. Specifically, we tested the costs for the surgical and medical treatments according to various time horizons to explore a break-even point for the anti-reflux surgery. A sensitive probability analysis was conducted to further assess the impact of uncertainty in the parameter estimations. Using a Monte Carlo microsimulation, the values of the parameters were randomly selected (1000 samples) from a beta distribution for the utility and the transition probabilities, and a gamma distribution for the costs. The scatter plot for incremental costs and QALYs derived from the Monte Carlo simulation was presented to evaluate the cost-effectiveness between the surgical and medical strategies for GERD.

\section{Results}

In our baseline case analysis, the anti-reflux surgery was less expensive and more effective treatment than the medical treatment with PPIs among severe GERD patients. In a 10-year time horizon, the model predicted that the costs were \$9696 and \$10 247 for the surgical and medical treatments, respectively. The predicted QALYs were also higher in the surgical strategy (7.05 QALYs) than in the medical strategy (5.87 QALYs) (Table 2).

Table 3 shows the results of the one-way sensitivity analysis according to changes in costs, utilities, and transition probabilities. The model was most sensitive to changes in costs as compared with other parameters. When the costs for PPI medication decreased to
$25 \%$ and the costs for surgery increased to $25 \%$ of the baseline case model, the costs per QALY for anti-reflux surgery were $\$ 1479.5$ and $\$ 1362.4$, respectively. However, when we changed the utilities and transition probabilities in the model, the anti-reflux surgery was still the dominant strategy that was both more effective and less expensive. A similar result was shown even when we applied the operative-mortality at $0.8 \%$ per year in the model.

To investigate the change in cost for follow-up periods, the cumulative costs were calculated between the medical and surgical strategies (Fig. 2). In the first year of follow-up, the costs for the surgical strategy (\$5895.2) were approximately 2.6 times higher than those for the medical strategy ( $\$ 2276.8)$. However, differences in the costs between the 2 strategies decreased with follow-up time. At 9 years of follow-up, the costs for the medical strategy exceeded those for surgical strategy (costs for surgical strategy $=\$ 9306.7$; costs for medical strategy $=\$ 9521.2$ ).

We performed Monte Carlo microsimulation 1000 times to further explore the uncertainty in parameter estimation. Under the assumptions of a stochastic process, the majority of simulation results showed that the anti-reflux surgery was a less expensive and more effective strategy for severe GERD treatment compared with PPI medication (Fig. 3).

\section{Discussion}

In this study, we investigated a comparison of the costs and QALYs of both long-term medical and surgical therapies for middle-aged patients with severe GERD. Our results showed that anti-reflux surgery is a more effective and less expensive treatment for severe GERD patients who require a continuous double dose of PPI. These results were consistent with the majority of modelingbased studies that reported GERD surgery as a cost-effective alternative to long-term maintenance therapy with PPIs. ${ }^{23-26}$ Several trial-based economic evaluations also demonstrated anti-reflux surgery was a cost-effective treatment for GERD patients. ${ }^{27-29}$ However, a few studies based on Markov modeling suggested PPI medication was preferred in terms of cost saving based on similar effectiveness. ${ }^{30-32}$

The differences can be largely due to assumptions about the effectiveness of medication and surgical strategies. Most studies that favored medical strategy over surgical strategy, ${ }^{30,32}$ assumed that the difference of utility between symptom-free and symptomatic GERD was only 0.01 , based on expert opinions or previous clinical findings (eg, early 1990's surgery cohort). ${ }^{33,34}$ However, relatively recent clinical trials reported that anti-reflux surgery continued to 
Table 3. One-way Sensitivity Analyses

\begin{tabular}{|c|c|c|}
\hline Category & Range & ICER for surgery ( $\$ / Q A L Y)$ \\
\hline \multicolumn{3}{|l|}{ Change in costs } \\
\hline \multicolumn{3}{|c|}{ Change in medical condition } \\
\hline \multirow[t]{2}{*}{ Decrease to $25 \%$} & Double dose of PPI: $\$ 874.6$ & 1479.5 \\
\hline & More than triple dose of PPI: $\$ 1167.5$ & \\
\hline \multirow[t]{2}{*}{ Increase to $25 \%$} & Double dose of PPI: $\$ 1457.7$ & Dominate \\
\hline & More than triple dose of PPI: $\$ 1945.9$ & \\
\hline \multicolumn{3}{|c|}{ Change in surgery condition } \\
\hline \multirow[t]{3}{*}{ Decrease to $25 \%$} & First surgery: $\$ 4084.2$ & 1362.4 \\
\hline & Surgery: $\$ 354.1$ & \\
\hline & Repeat-surgery: $\$ 3730.1$ & \\
\hline \multirow[t]{3}{*}{ Increase to $25 \%$} & First surgery: $\$ 6807.0$ & Dominate \\
\hline & Surgery: $\$ 590.2$ & \\
\hline & Repeat-surgery: $\$ 6216.8$ & \\
\hline \multicolumn{3}{|l|}{ Change in QALY } \\
\hline Commay et al, $2008^{31}$ & Within one year after surgery: 0.981 & Dominate \\
\hline \multirow[t]{3}{*}{ Funk et al, $2015^{25}$} & Surgery: 1.000 & \\
\hline & Symptom control with PPI: 0.990 & \\
\hline & Symptom uncontrolled with PPI: 0.940 & \\
\hline \multicolumn{3}{|c|}{ Change in transition probability } \\
\hline \multicolumn{3}{|c|}{ Change in medical condition } \\
\hline Decrease to $25 \%$ & Symptom uncontrolled rate with medication: 0.012 & Dominate \\
\hline Increase to $25 \%$ & Symptom uncontrolled rate with medication: 0.021 & Dominate \\
\hline \multicolumn{3}{|c|}{ Change in surgery condition } \\
\hline Death due to surgery & Operative mortality: $0.008^{19}$ & Dominate \\
\hline \multirow[t]{2}{*}{ Decrease to $25 \%$} & Repeat operation rate: 0.024 & Dominate \\
\hline & Symptom relapse rate after surgery: 0.005 & \\
\hline \multirow[t]{2}{*}{ Increase to $25 \%$} & Repeat operation rate: 0.040 & Dominate \\
\hline & Symptom relapse rate after surgery: 0.009 & \\
\hline
\end{tabular}

ICER, incremental cost-effectiveness ratio; PPI, proton pump inhibitors; QALY, quality-adjusted life years.

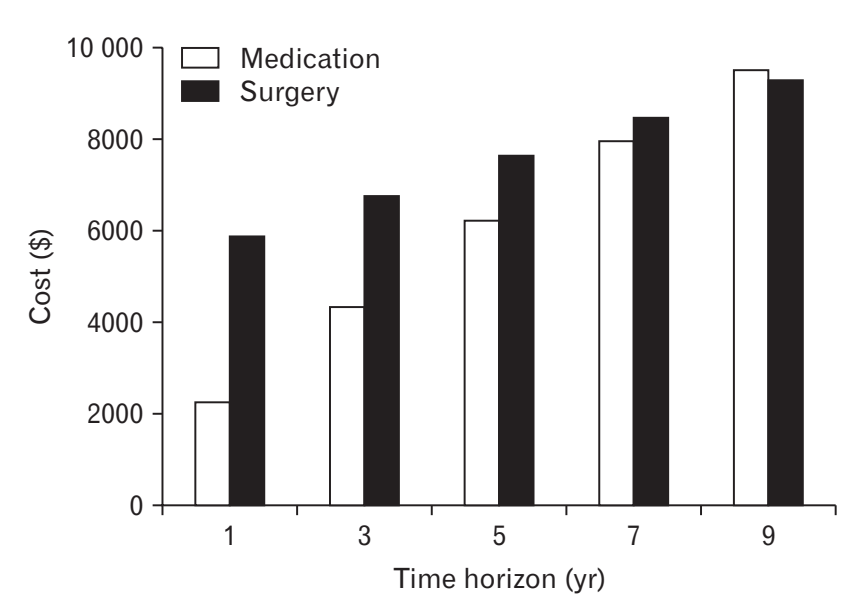

Figure 2. One-way sensitivity analysis according to various time horizons.

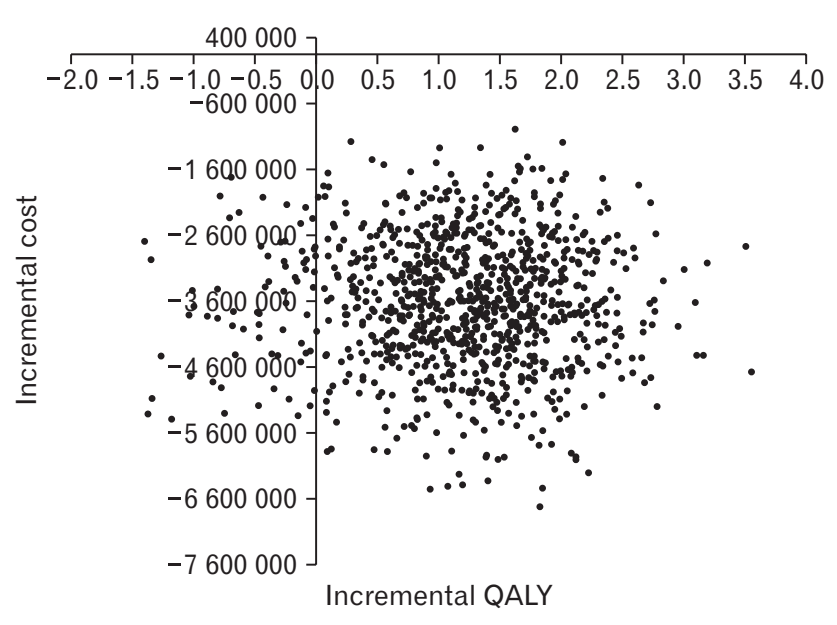

Figure 3. Incremental cost and quality-adjusted life years (QALYs) for anti-reflux surgery compared with proton pump inhibitor therapy. Cost-effectiveness stochastic uncertainty results based on 1000 bootstrap samples. 
provide better symptom relief of GERD for several years that was closely related to improved QoL as compared with the medical treatment with PPIs. ${ }^{21,35,36}$ Our results of a survey on EQ-5D also showed significant improvement of $\mathrm{QoL}$ after anti-reflux surgery (baseline $0.72,2$ weeks after surgery 0.83 ) which was in line with 2 UK trials. They reported that the utility value based on EQ-5D for GERD patients at baseline and at 1 year after surgery were approximately 0.7 and 0.8 , respectively. ${ }^{29,37}$ Although direct comparison between our results and the other studies was difficult because of both the short follow-up time in our study and the difference in cultural background, the clinical trial data supported the assumption of higher QoL in the surgical group compared to the medication group. Further study is needed to compare the QOL for GERD patients under a more controlled clinical setting.

In addition, the inconsistency in results can be partially explained by differences in either medical costs across countries or in methodology across studies. For example, the costs for laparoscopic Nissen fundoplication differed by approximately 3000 Canadian dollars ( $\$ 3091$ vs $\$ 6537$ ) in 2 Canadian studies, ${ }^{26,31}$ which implied that there could be significant differences in cost estimation according to data sources and cost methods. To reduce the variations of unit costs and quantities in cost assumptions, we estimated the costs for surgery using real-world data that entirely consisted of antireflux surgery cases in Korea. Our cost analysis was based on the sum of the diagnosis-specific method, which is one of the gross cost methods that calculates only the specific disease-related medical expenditures from the total expenditures of patients with the disease. ${ }^{38}$ The cost ratio comparing between surgery versus medication was estimated to be 1.6 at 3 years of follow-up, which was similar to the results of a trial-based UK study working with actual observed patient data (cost ratio $=1.3){ }^{29}$ Trial-based economic evaluations include the collection of patient-level utilization resource data, thus our results using real-world patient data might be closer to trialbased studies.

The break-even point in costs for anti-reflux surgery was estimated to be 9 years in our results, which means the surgical treatment was less expensive when the expected time of medical maintenance was more than 9 years. The break-even point for surgery over medication varied from between 2 to 27 years; however, most studies suggested it was under 5 years ${ }^{26,37}$ or 10 years. ${ }^{27,32}$ Previous evidence has confirmed that anti-reflux surgery was quite costly, but annual post-surgical maintenance costs were constantly lower than medication therapy. ${ }^{24-26,37}$ In our cost analysis using a claims database, the annual average medical costs for the surgery group continued to decline from $\$ 621.6$ at the second year to $\$ 200.4$ in the fifth year after anti-reflux surgery, whereas the medication group had a consistent cost of approximately $\$ 1300$ per year for the 5 years of follow-up (data was not shown).

This study used the decision tree for 1 year and a Markov model which has several life-long health statuses. The model targeted the patients with severe GERD, thus we assumed that the initial status of medication was taking a double dose of PPI (eg, omeprazole $40 \mathrm{mg} /$ day). If patients failed to control the symptoms with a double dose of PPI, they were assumed to receive more than the triple dose of PPI (eg, omeprazole $60 \mathrm{mg} / \mathrm{day}$ ). The assumptions related to PPI medication according to the health statuses in the model were similar to those of previous modeling-based economic assessments. ${ }^{25,26,30,32}$ The majority of previous studies included the health statuses of using a standard dose, double dose, and more than the triple dose (eg, omeprazole $60 \mathrm{mg} / \mathrm{day}$ or $80 \mathrm{mg} /$ day) of PPIs in the model according to the prognosis of GERD treatment. $^{39}$

This study had several limitations, leading one to be cautious of interpreting the results. First, the health status and the treatment failure rates in the model were based on previous clinical trials in Western countries, because relevant data was lacking in Korea. However, the success rates and the treatment patterns for GERD can vary across different medical environments. ${ }^{40}$ Second, this study was based on a health care perspective and did not account for indirect costs such as losses in productivity due to work absences. This could lead to the underestimation of the long-term economic benefits of anti-reflux surgery. Third, we did not consider the costs of complications between surgical and medical treatments. Dysphagia and gas-bloat syndrome can be side effects associated with GERD surgery. ${ }^{41}$ The long-term use of PPI was associated with various diseases, such as osteoporosis, dementia, infections, and cardiovascular disease. ${ }^{10}$ However, these issues could not be addressed in this study, because evidence of their impact on costs and clinical outcomes has been unknown. Fourth, our study could not consider specific medical costs not covered by health insurance. Those in the surgery group that require hospitalization are more likely to accrue medical costs not covered by health insurance than those in the medication group, which can underestimate the costs of GERD surgery. Fifth, medical costs and resources vary across regions, therefore generalization should be made carefully. Finally, we did not consider endoscopic procedures and the specific types of anti-reflux surgery in our model, because there has been insufficient cost-effectiveness data in Korea. Further clinical evidence for GERD treatment and their prognosis in Asian countries is necessary. 
Nevertheless, this study achieved a demonstration of the costeffectiveness of anti-reflux surgery in Korea. The cost-effectiveness of the surgery for GERD has been assessed through many studies in North America and Europe. However, in Asian countries, the economic evaluation of anti-reflux surgery has been rare. Although the prevalence of GERD in Asia has been relatively lower than that in Western countries, the rapidly increasing prevalence of GERD diagnoses and the higher PPI prescription rate are alarming. Thus, the findings of this study could be used as basic information for making practical guidelines and resource allocation for GERD treatment in Korea.

\section{Supplementary Materials}

Note: To access the supplementary tables mentioned in this article, visit the online version of Journal of Neurogastroenterology and Motility at http://www.jnmjournal.org/, and at https://doi. org/10.5056/jnm19188.

Acknowlegements: This study used National Health Insurance Service (NHIS)-customized data (NHIS-2018-1-158) provided by the NHIS. The authors declare no potential conflicts of interest with NHIS with respect to the authorship and/or publication of this article.

Financial support: This research was supported by a grant of the Korea Health Technology R\&D Project through the Korea Health Industry Development Institute, funded by the Ministry of Health \& Welfare, Republic of Korea (Grant No. HC17C0050) (http://www.mohw.go.kr). The funders had no role in study design, data collection and analysis, decision to publish, or preparation of the manuscript.

\section{Conflicts of interest: None.}

Author contributions: Jin-Won Kwon and Kyung Won Seo took a part in the design of the study; Susan Park, Soorack Ryu, and Jinseub Hwang analyzed the data; Susan Park wrote the manuscript; and Sungsoo Park and Joong-Min Park supported the clinical data and revised the manuscript. All authors contributed to interpreting the analyses and to critically revising the article, and approved the final draft.

\section{References}

1. Hunt R, Armstrong D, Katelaris P, et al. World gastroenterology organ- isation global guidelines: GERD global perspective on gastroesophageal reflux disease. J Clin Gastroenterol 2017;51:467-478

2. Eusebi LH, Ratnakumaran R, Yuan Y, Solaymani-Dodaran M, Bazzoli F, Ford AC. Global prevalence of, and risk factors for, gastro-oesophageal reflux symptoms: a meta-analysis. Gut 2018;67:430-440.

3. El-Serag HB, Sweet S, Winchester CC, Dent J. Update on the epidemiology of gastro-oesophageal reflux disease: a systematic review. Gut 2014;63:871-880

4. Kim KM, Cho YK, Bae SJ, et al. Prevalence of gastroesophageal reflux disease in Korea and associated health-care utilization: a national population-based study. J Gastroenterol Hepatol 2012;27:741-745.

5. Min BH, Huh KC, Jung HK, et al. Prevalence of uninvestigated dyspepsia and gastroesophageal reflux disease in Korea: a population-based study using the Rome III criteria. Dig Dis Sci 2014;59:2721-2729.

6. Peery AF, Dellon ES, Lund J, et al. Burden of gastrointestinal disease in the United States: 2012 update. Gastroenterology 2012;143:1179-1187, e3.

7. Shaheen NJ, Hansen RA, Morgan DR, et al. The burden of gastrointestinal and liver diseases, 2006. Am J Gastroenterol 2006;101:2128-2138.

8. Kim JJ, Jang EJ, Kim DH, Park H, Sohn HS. Proton pump inhibitors' use in Korea based on the national health insurance sample cohort database (2002-2013). Yakhak Hoeji 2018;62:171-178.

9. El-Serag H, Becher A, Jones R. Systematic review: persistent reflux symptoms on proton pump inhibitor therapy in primary care and community studies. Aliment Pharmacol Ther 2010;32:720-737.

10. Kinoshita Y, Ishimura N, Ishihara S. Advantages and disadvantages of long-term proton pump inhibitor use. J Neurogastroenterol Motil 2018;24:182-196.

11. Davis CS, Baldea A, Johns JR, Joehl RJ, Fisichella PM. The evolution and long-term results of laparoscopic antireflux surgery for the treatment of gastroesophageal reflux disease. JSLS 2010;14:332-341.

12. Catarci M, Gentileschi P, Papi C, et al. Evidence-based appraisal of antireflux fundoplication. Ann Surg 2004;239:325-337.

13. Gawron AJ, French DD, Pandolfino JE, Howden CW. Economic evaluations of gastroesophageal reflux disease medical management. Pharmacoeconomics 2014;32:745-758.

14. Park S, Park JM, Kim JJ, et al. Multicenter prospective study of laparoscopic nissen fundoplication for gastroesophageal reflux disease in Korea. J Neurogastroenterol Motil 2019;25:394-402.

15. Park S, Kwon JW, Park JM, Park S, Seo KW. Treatment pattern and economic burden of refractory gastroesophageal reflux disease patients in Korea. J Neurogastroenterol Motil 2020;26:281-288.

16. Katz PO, Gerson LB, Vela MF. Guidelines for the diagnosis and management of gastroesophageal reflux disease. Am J Gastroenterol 2013;108:308-328.

17. Jung HK, Hong SJ, Jo Y, et al. [Updated guidelines 2012 for gastroesophageal reflux disease.] Korean J Gastroenterol 2012;60:195-218. [Korean]

18. Jacobs JP, Mavroudis C, Jacobs ML, et al. What is operative mortality? Defining death in a surgical registry database: a report of the STS congenital database taskforce and the joint EACTS-STS congenital database committee. Ann Thorac Surg 2006;81:1937-1941 
19. Dominitz JA, Dire CA, Billingsley KG, Todd-Stenberg JA. Complications and antireflux medication use after antireflux surgery. Clin Gastroenterol Hepatol 2006;4:299-305.

20. Fleurence RL, Hollenbeak CS. Rates and probabilities in economic modelling: transformation, translation and appropriate application. Pharmacoeconomics 2007;25:3-6.

21. Galmiche JP, Hatlebakk J, Attwood S, et al. Laparoscopic antireflux surgery vs esomeprazole treatment for chronic GERD: the LOTUS randomized clinical trial. JAMA 2011;305:1969-1977.

22. Kim SH, Ahn J, Ock M, et al. The EQ-5D-5L valuation study in Korea. Qual Life Res 2016;25:1845-1852.

23. Bojke L, Hornby E, Sculpher M; REFLUX trial team. A comparison of the cost effectiveness of pharmacotherapy or surgery (laparoscopic fundoplication) in the treatment of GORD. Pharmacoeconomics 2007;25:829-841.

24. Epstein D, Bojke L, Sculpher MJ; REFLUX trial group. Laparoscopic fundoplication compared with medical management for gastro-oesophageal reflux disease: cost effectiveness study. BMJ 2009;339:b2576.

25. Funk LM, Zhang JY, Drosdeck JM, Melvin WS, Walker JP, Perry KA. Long-term cost-effectiveness of medical, endoscopic and surgical management of gastroesophageal reflux disease. Surgery 2015;157:126-136.

26. Romagnuolo J, Meier MA, Sadowski DC. Medical or surgical therapy for erosive reflux esophagitis: cost-utility analysis using a Markov model. Ann Surg 2002;236:191-202.

27. Cookson R, Flood C, Koo B, Mahon D, Rhodes M. Short-term cost effectiveness and long-term cost analysis comparing laparoscopic Nissen fundoplication with proton-pump inhibitor maintenance for gastrooesophageal reflux disease. Br J Surg 2005;92:700-706.

28. Faria R, Bojke L, Epstein D, Corbacho B, Sculpher M; REFLUX trial group. Cost-effectiveness of laparoscopic fundoplication versus continued medical management for the treatment of gastro-oesophageal reflux disease based on long-term follow-up of the REFLUX trial. Br J Surg 2013;100:1205-1213.

29. Goeree R, Hopkins R, Marshall JK, et al. Cost-utility of laparoscopic Nissen fundoplication versus proton pump inhibitors for chronic and controlled gastroesophageal reflux disease: a 3-year prospective randomized controlled trial and economic evaluation. Value Health 2011;14:263273.

30. Arguedas MR, Heudebert GR, Klapow JC, et al. Re-examination of the cost-effectiveness of surgical versus medical therapy in patients with gas- troesophageal reflux disease: the value of long-term data collection. Am J Gastroenterol 2004;99:1023-1028.

31. Comay D, Adam V, da Silveira EB, Kennedy W, Mayrand S, Barkun AN. The Stretta procedure versus proton pump inhibitors and laparoscopic Nissen fundoplication in the management of gastroesophageal reflux disease: a cost-effectiveness analysis. Can J Gastroenterol 2008;22:552-558.

32. Heudebert GR, Marks R, Wilcox CM, Centor RM. Choice of longterm strategy for the management of patients with severe esophagitis: a cost-utility analysis. Gastroenterology 1997;112:1078-1086.

33. Spechler SJ, Lee E, Ahnen D, et al. Long-term outcome of medical and surgical therapies for gastroesophageal reflux disease: follow-up of a randomized controlled trial. JAMA 2001;285:2331-2338.

34. Klapow JC, Wilcox CM, Mallinger AP, et al. Characterization of longterm outcomes after Toupet fundoplication: symptoms, medication use, and health status. J Clin Gastroenterol 2002;34:509-515.

35. Anvari M, Allen C, Marshall J, et al. A randomized controlled trial of laparoscopic Nissen fundoplication versus proton pump inhibitors for the treatment of patients with chronic gastroesophageal reflux disease (GERD): 3-year outcomes. Surg Endosc 2011;25:2547-2554.

36. Grant AM, Cotton SC, Boachie C, et al. Minimal access surgery compared with medical management for gastro-oesophageal reflux disease: five year follow-up of a randomised controlled trial (REFLUX). BMJ 2013;346:f1908

37. Grant A, Wileman S, Ramsay C, et al. The effectiveness and costeffectiveness of minimal access surgery amongst people with gastrooesophageal reflux disease - a UK collaborative study. The REFLUX trial. Health Technol Assess 2008;12:1-181, iii-iv.

38. Akobundu E, Ju J, Blatt L, Mullins CD. Cost-of-illness studies : a review of current methods. Pharmacoeconomics 2006;24:869-890.

39. Klinkenberg-Knol EC, Festen HP, Jansen JB, et al. Long-term treatment with omeprazole for refractory reflux esophagitis: efficacy and safety. Ann Intern Med 1994;121:161-167.

40. Fock KM, Talley N, Goh KL, et al. Asia-Pacific consensus on the management of gastro-oesophageal reflux disease: an update focusing on refractory reflux disease and Barrett's oesophagus. Gut 2016;65:14021415.

41. Yadlapati R, Hungness ES, Pandolfino JE. Complications of antireflux surgery. Am J Gastroenterol 2018;113:1137-1147. 